\title{
Imersões, fluxos e desafios em uma etnografia no Tinder
}

\author{
SheIla CAVALCANTE Dos SANTOS \\ Universidade Federal do Paraná, Curitiba, Paraná, Brasil \\ sheucavalcante@gmail.com
}

DOI 10.11606/issn.2316-9133.v29i2pe175168

\begin{abstract}
resumo Neste artigo trago um relato acerca da metodologia do trabalho de campo realizado no Tinder, aplicativo para celular que proporciona a busca afetivo-sexual on-line, quando da minha pesquisa para o Mestrado em Antropologia com usuários e usuárias do aplicativo. Assim como na prática etnográfica analógica, a etnografia em contextos digitais apresenta desafios, alguns dos quais próprios às relações estabelecidas através de tais ambientes, conforme vivenciei durante o fluxo da pesquisa, que envolveu a circulação por três capitais do país. Assim, discuto aspectos particularmente marcantes do percurso de campo que se relacionam, em grande medida, aos modos de fazer característicos dos usos desses aplicativos e que podem esbarrar em questionamentos sobre ética da pesquisa. palavras-chave Etnografia. Metodologia. Fluxos on-line e off-line. Intimidade.
\end{abstract}

\section{On immersion, flows and challenges of doing ethnography on Tinder}

abstract The article describes the methodology of the fieldwork performed on Tinder, an application that provides the affective-sexual search online. It is the bases of my research conducted during the master in Anthropology with users of this application. Just like in analog ethnographic practice, ethnography in digital contexts presents challenges, some of which are proper to the relationships established through such environments, as I experienced during the flow of the research, which involved the circulation through three capitals of the country. Thus, I discuss particularly outstanding aspects of the fieldwork, largely related to the typical ways of using these programs and that may bump into questions about research ethics.

keywords Ethnography. Methodology. Online and offline flows. Intimacy.

\section{Imersiones, flujos y desafios de una etnografía em Tinder}

resumen $\mathrm{El}$ artículo describe la metodología del trabajo de campo realizado en Tinder, una aplicación que proporciona la búsqueda afectivo-sexual en línea. Son las bases 
de mi investigación realizada durante el master en Antropología con los usuarios de esta aplicación. Al igual que en la práctica etnográfica analógica, la etnografía en contextos digitales presenta desafíos, algunos de los cuales son propios de las relaciones que se establecen a través de tales entornos, como experimenté durante el flujo de la investigación, que implicó la circulación por tres capitales del país. Así pues, examino aspectos particularmente destacados del trabajo de campo, relacionados en gran medida con las formas típicas de utilizar estos programas y que pueden tropezar con cuestiones sobre la ética de la investigación.

palabras clave Etnografía. Metodología. Flujos online y off-line. Intimidad.

\section{Digital e analógico em uma pesquisa etnográfica}

Entre 2016 e 2017 pesquisei, a partir de uma abordagem etnográfica, a experiência de uso do Tinder, aplicativo para celular que proporciona a busca afetivo-sexual on-line. $\mathrm{Na}$ ocasião, procurei compreender formas pelas quais tal aplicativo se insere na dinâmica das relações interpessoais e interfere na sociabilidade e vivência da intimidade de quem faz uso. Em diálogo com um instrumental teórico que atentou para a agência do indivíduo no mundo da vida (SCHÜTZ; LUCKMANN 2003), verifiquei que, para aquelas pessoas, o Tinder figurou como uma alternativa a mais e um meio ativo nos devires da busca pelo outro. Integra um movimento de procura e afastamento, de negociação e tensão, que comporta tanto expectativas de afinidade e reciprocidade nas trocas intersubjetivas como a valorização da autonomia e da escolha como cernes do projeto individual ${ }^{1}$.

Ao pesquisar sobre as experiências vivenciadas por meio do Tinder, dentre outras abordagens que compuseram o trabalho final, fiz um esforço de descrição e análise sobre as especificidades daquele estudo, desenrolado em meio digital e analógico, em relação ao que Marcus (2004) descreveu como mise-en-scène malinowskiana clássica da pesquisa de campo. Esta abrange, segundo o autor, características essenciais das "formas e normas" de como o trabalho de campo é tratado quando pensado e ensinado contemporaneamente. Para ele, a pesquisa de campo profissional em antropologia foi concebida de modo folclórico, papel que ela desempenha na formação dos estudantes do ofício. Um imaginário, em suas palavras, teatral ou fílmico, que permeia o que seria o método antropológico. Recheia esse imaginário clássico da pesquisa de campo aspectos como "a imagem do 'primeiro contato' e da exaltada alteridade mental" e o "enfático e vigoroso estar lá” (MARCUS 2004: p.148).

A desestabilizar e pôr em xeque esse imaginário estão aspectos característicos da contemporaneidade, tais como a fragmentação de culturas e populações estabelecidas, em certa medida, o aspecto mais cosmopolita dos lugares e a própria crítica política e ética recebida (e autorreferida) da Antropologia nas relações tradicionais de pesquisa. Mas

\footnotetext{
${ }^{1}$ A pesquisa foi desenvolvida durante o curso do mestrado no Programa de Pós-Graduação em Antropologia da Universidade Federal da Paraíba, sob a orientação do prof. Dr. Mauro Guilherme Pinheiro Koury, intitulada "Curtir ou não curtir: experimentações a partir do Tinder".
} 
também questões mais intimamente relacionadas à função documental da Antropologia frente a um mundo no qual a produção de conhecimento sobre o outro apresenta hoje "muitas formas de representação, mais competitivas e apropriadas quando comparadas a sua" (MARCUS 2004: p.150). Em suma, o autor tanto situa a antropologia num campo de disputas de narrativas com outras formas políticas e as possíveis interrelações entre elas como trata das especificidades do que chamou de campos multilocalizados (multi-sited). Para Marcus, tais campos são locais de investigação múltiplos e heterogêneos, que desafiam e desestabilizam os tropos normativos do trabalho de campo clássico, o que impõem ao pesquisador, além dos atos reflexivos de descrição e interpretação, uma postura ativa/colaborativa.

Seguindo essa linha de pensamento, é possível situar a intensificação dos usos de ambiente digitais - a partir do início deste século, especialmente com o advento da Web $2.0^{2}$ - como um ponto de desestabilização da mise-en-scène malinowskiana clássica da pesquisa de campo. Na última década, essa nova arquitetura digital acentuou a maior interconexão entre on e off-line no dia-a-dia, dentre outros aspectos, tornando possível a proliferação de redes sociais digitais tal como conhecemos hoje: "plataformas desenhadas para se introduzir na vida cotidiana dos usuários" (DIJCK 2016: p.26, tradução livre da autora). Como redes de comunicação concebidas em princípio para agregar uma comunidade de usuários, uma vez incorporadas por grandes empresas passaram a operar também como complexos negócios que articulam sistemas algorítmicos à coleta, entrecruzamento, categorização, venda de dados pessoais dos usuários. Esse fenômeno do crescimento e da interconexão entre as plataformas digitais impulsionou-nos a transpor parte da nossa vida social, pessoal, profissional - e mesmo sexual/amorosa - para o ambiente digital.

Habitamos hoje um ecossistema que "passou de uma comunicação em rede para uma sociedade modelada por plataformas, e de uma cultura participativa para uma verdadeira cultura da conectividade" (DIJCK 2016: p.12, tradução livre da autora). A conectividade, enquanto infraestrutura global fortificada pela interatividade das tecnologias digitais, retroalimenta a "sociedade em rede" e ocupa lugar cada vez mais central nas nossas relações cotidianas. Inseridas nessa cultura da conectividade, redes sociais para fins de relacionamento, como o Tinder, articulam uma intenção projetada ${ }^{3}$ relativa à descoberta online de pessoas com interesses comuns, cujo significado simbólico marcante alude à busca e ao encontro afetivo-sexual. Uma busca que começa no on-line e pode ou não se estender ao encontro presencial.

\footnotetext{
${ }^{2}$ Santaella (2014) destaca que o termo foi propagado a partir de 2004 por Tim O’Reilly, para designar uma nova onda de serviços, compartilhamento de dados, organização e publicação de informações on-line, caracterizada pela participação em larga escala do usuário e pela geração e compartilhamento massivo de dados. A intensificação dos usos das mídias sociais, blogs e wikis é um exemplo desse fenômeno.

${ }^{3}$ Projeto aqui no sentido empregado por Velho (2003, p. 40), como "conduta organizada para atingir finalidades específicas", um modo de antecipação futura da trajetória.
} 
Foi nesse tipo multilocalizado de campo, no qual vários contextos e escalas de pesquisa estiveram relacionados, que se situou o meu trabalho etnográfico. $\mathrm{Na}$ época, alguns dos desafios do que hoje se chama de Antropologia Digital (MILLER; HORST 2015) foram sentidos, apesar de correlacionados com os desafios e fazeres presentes nas etnografias analógicas. Naquele momento, foi mandatório fazer questionamentos e atualizações de procedimentos técnicos, metodológicos e éticos, ao passo em que incitou reflexões e readaptações do fazer etnográfico, inclusive, das (rel)ações estabelecidas com o campo e os sujeitos.

Assim, neste artigo, relatarei alguns desafios que o campo impôs à pesquisa e as experimentações que fiz para lidar com eles. Sem ter a pretensão de aprofundar uma crítica às concepções clássicas sobre a etnografia e o fazer etnográfico, adiante abordarei sobre artifícios usados para "estranhar" uma plataforma digital na qual era nativa, apresentando os modos como até então eu percebia aquele ambiente. Em seguida, tematizo os "deslizamentos" (LEITÃO; GOMES 2011) on-line/off-line, aspectos marcantes no desenho metodológico do estudo. Associo a esses dois âmbitos os componentes da imersão nos modos de operação característicos do uso dos aplicativos e das tensões e negociações das expectativas e desejos sexuais e afetivos em campo.

\section{Mais uma nativa pesquisadora}

Autores como Pelúcio (2016), Bozon (2004), Giddens (1993), dentre outros, apontam que desde os 1960 vivenciam-se no âmbito cotidiano os efeitos políticos de amplas mudanças sociais, especialmente dos debates e lutas feministas e das modificações nas relações de gênero, bem como, em tempos mais recentes, da politização de temas relacionados às sexualidades não heterossexuais. Esse fenômeno tanto incita a repensar e reformular arranjos e cenários domésticos, das relações sexuais e do relacionamento como vem dotando as pessoas de uma nova linguagem da intimidade, do sexo, dos desejos, do corpo. As esferas pública e privada vêm se retroalimentando no que tange às práticas, expectativas e enunciados amorosos e sexuais. Para Illouz (2011), a vida afetiva passa a ter lugar de destaque enquanto um texto público. É possível perceber que esse texto vem sendo atualizado nos mais diversos espaços públicos, seja nas rodas de conversa, seja nos programas televisivos ou nas redes sociais.

Em meio a esse contexto de publicização da afetividade e da sexualidade, tal como ocorreu com grande parte dos meus informantes, cheguei ao Tinder por intermédio de conhecidos nas conversas de bar, onde quem usava incentivava os demais a experimentar, e também pela particular insistência de um amigo. Naquela época, 2014, o uso de aplicativos para conhecer pessoas com as quais se pudesse relacionar afetiva ou sexualmente era novidade entre o público heterossexual, e inspirava certo ceticismo - que eu também sentia. Em dado momento, acabei por sucumbir às insistências e à minha curiosidade. Por que não usar a tecnologia para conhecer novas pessoas (ou potenciais parceiros)? 
Durante quase dois anos fiz uso do aplicativo até ter a percepção daquele instrumento, carregado de técnica e emotividade, materialidade e virtualidade ${ }^{4}$, como possível campo de estudos. Em meio às minhas experiências, via e participava de "troca de figurinhas" com outros usuários e usuárias, amigos ou conhecidos, em seus usos, interesses, expectativas, encontros e desencontros, prazeres, medos ou decepções proporcionados pelo $a p p^{5}$. Cancelei meu perfil várias vezes, para depois reinstalar o aplicativo e retomar a prática de ver perfis, analisá-los, aprová-los ou não e vivenciar histórias por ele proporcionadas.

Desse modo, as vivências e considerações feitas durante a pesquisa e nos textos que dela decorrem são permeadas, também, pelo meu olhar de "nativa" do aplicativo, associado ao esforço de distanciamento reflexivo que requer a análise antropológica. $O$ "estranhamento" necessário à análise feito neste trabalho, como propôs Velho (1981) ao avaliar as categorias distância e objetividade na pesquisa antropológica feita em locais de familiaridade, longe de ser um ato de exotismo ou de distanciamento radical, é a constatação da amplitude destas realidades, que são muito mais complexas que as histórias que vivenciei. Logo, o esforço é o de "confrontar intelectualmente, e mesmo emocionalmente, diferentes versões e interpretações existentes a respeito de fatos, situações" (VELHO 1981: p.13), pontos de vistas que ali se desenrolam; os meus, os das pessoas com quem interagi, os de outros atores que compuseram aqueles cenários.

Foi nessa perspectiva, dos enredos desenrolados numa intrincada malha ${ }^{6}$ (INGOLD 2015) onde afetos e não-afetos são entrelaçados, num fluxo contínuo de pessoas e personagens, que me inseri como pesquisadora. Durante dois meses, em caráter exploratório, fiz perfis e observei a dinâmica de sete aplicativos de encontros ${ }^{7}$, com a finalidade de definir qual seria o campo da pesquisa, dentro do universo dos aplicativos. Programas como esse são conhecidos como apps de encontro, de paquera, de namoro ou de

\footnotetext{
${ }^{4}$ Uso os termos virtual e virtualidade como sinônimos de digital ou on-line. O faço não para demarcar o virtual como um setor específico da vida, mas para me referir aos diversos ambientes da internet enquanto parte do cotidiano e nele imiscuído.

${ }^{5}$ App, aplicativo, programa, plataforma são nomenclaturas usuais para designar softwares utilizados em dispositivos móveis.

${ }^{6}$ Utilizando o termo por inspiração na filosofia de Henri Lefebvre, e num arcabouço conceitual inspirado em Heidegger e Deleuze, Ingold (2012) propõe o uso de malha com uma alternativa, segundo ele, à manutenção da ideia de agência fetichizada dos objetos em sua distinção com o sujeito, feita pela teoria ator-rede de Bruno Latour. Propõe, assim, com a malha, a ideia de dinamicidade e permeabilidade de relações cujos termos são continuamente formados, "e não enquanto entidades conectadas com limites interiores ou exteriores" (ibid: p.40). O autor fala em um "emaranhado de coisas", de linhas entrelaçadas, linhas de fluxo e contrafluxo que seguem em movimento e acontecem na vida e onde há vida. Por esse caráter de fluxo e dinamicidade de vários elementos emaranhados, me parece adequado o uso de tal termo no contexto dessa pesquisa.

${ }^{7}$ Tinder, Hot or Not, Happn, Okcupid, Kickoff, Down e Anomo foram os aplicativos. Os dois últimos foram descartados logo no início, porque não havia usuários nas regiões onde usei. Maiores informações sobre eles estão disponíveis em matéria do portal Canal Tech.
} 
relacionamento, e combinam parâmetros tais como geolocalização ${ }^{8}$, preferências pessoais e processamento algorítmico para que os usuários busquem, em seu mobile ${ }^{9}$, pessoas com as quais possam ter relações afetivas, sexuais ou amorosas. Utilizando-os, configurei meus perfis com o que julguei serem fotos minhas discretamente atrativas - discretas, pela seriedade da pesquisa, atraentes, porque precisaria chamar a atenção dos potenciais participantes, num campo onde a imagem é um chamariz essencial. Optei, ao final desse período, por tornar o Tinder o ambiente de campo principal, uma vez que nele constava um maior número de perfis e interações. Permaneci com o perfil ativo durante 13 meses.

Aquela foi uma época de transição entre os atos da usuária, acostumada com os trâmites do estabelecimento de relações pelo aplicativo, e o exercício de uma alteridade que não poderia ser radical. Coloquei na identificação no meu perfil a frase "Pesquisadora das ciências sociais interessada nas experiências e histórias das pessoas que ali se encontravam" e curti o máximo de perfis, na esperança de que ocorressem matches - que na linguagem do aplicativo, são as combinações que ocorrem quando duas pessoas curtem mutuamente o perfil da outra, podendo, assim, iniciar uma conversa por um chat privado. Adotei como estratégia daquele reinício experimentar algo novo em meio a uma prática familiar (VELHO 1981), na tentativa de me dessensibilizar às características que minha familiaridade talvez não me permitisse perceber. Assim, paradoxalmente, decidi iniciar esse processo de estranhamento usando-o "em casa".

Explico. Quando conheci e passei a usar o Tinder o fiz porque estava estrangeira numa nova cidade. Na acepção simmeliana (SIMMEL 2005), estrangeiro é alguém que chega numa localidade e nela permanece, porém dotado da liberdade de ir e vir, do potencial de partir a qualquer tempo. Pode fazer e estreitar relações, adentrar naquele território, mas não carrega o senso de pertencimento. Naquela época, meu subterfúgio principal para usar o aplicativo foi o fato de estar fora da minha zona de familiaridade. Em minha própria experiência, aquele recurso tecnológico veio como um facilitador oportuno para conhecer novas pessoas, penetrar no lugar. Minha percepção, até aquele momento, era a de que usar o aplicativo seria uma alternativa possível para uma forasteira ampliar seu círculo de relações.

De outro modo, nunca havia me ocorrido ligar o Tinder "em casa" - em minha cidade natal -, justamente porque explorar o lugar ou estabelecer novas relações não prescindia, em princípio, da mediação tecnológico-comunicativa de um app de paquera. Lá, eu tinha um

\footnotetext{
${ }^{8}$ Recurso móvel de localização geográfica em tempo real por meio do GPS. A geolocalização permite que os aplicativos acessem seus dados geográficos, ou seja, sua localização. Isso possibilita tanto ao usuário detectar locais do seu interesse - tomando como referência a sua própria localização ou outra por ele especificada como outros usuários lhe localizarem. O recurso está presente nos mais diversos programas para mobile, destinados a encontrar, por exemplo, comércios, serviços, ruas ou pessoas, como é o caso dos aplicativos de paquera. A geolocalização é um dos diferenciais dos aplicativos desse tipo em relação a outros modos on-line de buscar parceiros.

${ }^{9}$ Em tecnologia da informação, mobile são aparelhos e serviços tecnológicos direcionados à comunicação móvel, tais como os smartphones e tablets.
} 
círculo de relações presenciais consolidado, que me bastava. Por isso, quando retornei à cidade para uma breve temporada não me ocorreu nada mais "estranho" que operá-lo naquele que era o meu ambiente de relações já estabelecidas. Seria, portanto, uma novidade ver ali a dinâmica de busca de relações afetivas e sexuais através do aplicativo. A "nova" experiência me rendeu algumas conversas valorosas pelo app e uma entrevista presencial.

Esse meu exercício de estranhamento inicial se mostrou interessante não apenas pelas conversas que proporcionou. Com o decorrer da pesquisa, ao dialogar com outros usuários/as vi que muitos deles usavam o app tanto "em casa" como fora dela, sob justificativas diversas. Se para mim, num dado momento, o app de paquera representou apenas um modo de conhecer pessoas numa localidade pouco explorada, para outros ele figurava como mais uma forma de jogar com as possibilidades de proximidade e de distância, virtualidade e presencialidade, no estabelecimento de relações interpessoais cotidianas. Um diálogo multidimensional com o lugar físico no qual se está, adicionando uma nova possibilidade de estabelecer relações ali. Em alguns casos, era uma alternativa ou incremento aos espaços de socialidade que envolviam amigos ou colegas de trabalho. Em outros, um modo de interagir com um próximo (ou um distante) a quem o acesso presencial era dificultado pelos mais diversos motivos. Ou, para aqueles que estavam em locais de trânsito, de curta estadia ou eram estrangeiros (SIMMEL 2005), como eu fui, o aplicativo tinha a função de colaborar no estabelecimento de relações, mesmo que transitórias, num novo território. O Tinder se mostrava, então, um recurso versátil para vencer diversificadas fronteiras sociais, espaciais, emocionais.

Esse aspecto da territorialidade correlacionado às plataformas digitais em suas possibilidades relacionais já fora explorado em alguns trabalhos anteriores. Em sua pesquisa sobre relações interpessoais de participantes de uma comunidade do Orkut, Parreiras (2008) trata o ciberespaço como espaço desterritorializado, e se utiliza do conceito de territorialidade itinerante de Perlongher, que o aborda a partir de constantes junções entre derivas e devires, e não como algo fixo. Assim, o digital territorializa e reterritorializa de modo ágil, constante e com distintas temporalidades. Silva e Takeuti (2010), Silva (2009) e Silva (2016) falam de um namoro virtual e desterritorializado, com capacidade de se manifestar em diferentes locais e situações, mas sem estar preso a coordenadas espaçotemporais.

A partir desse primeiro experimento, passei a ligar o Tinder em meu percurso diurno, nos lugares onde eu transitava cotidianamente, à noite, no geral em casa, e nas viagens, tal qual faziam muitos dos meus entrevistados/as. $\mathrm{O}$ app permite configurar as buscas a partir do sexo do usuário, o/s sexo/s de interesse, distância da busca e faixa etária. Alinhada com esses filtros, busquei, no app e fora dele, homens e mulheres, na faixa etária entre 20 e 44 anos, que procuravam ou já haviam procurado no Tinder parceria afetiva e/ou sexual do sexo oposto ${ }^{10}$.

\footnotetext{
${ }^{10} \mathrm{Na}$ época da pesquisa, as poucas publicações que encontrei no âmbito das ciências sociais sobre o uso de apps de paquera, em especial na língua portuguesa ou relacionadas com o contexto brasileiro, tematizavam homens
} 
Usando o aplicativo, o tempo/espaço de interação é potencialmente qualquer um (basta ter o aplicativo instalado e acesso à internet) e o encontro presencial entre usuários/as, de modo geral, é valorizado, quando não esperado ${ }^{11}$. Por isso, desde o desenho do projeto de pesquisa os encontros presenciais com os usuários e usuárias foram cogitados. Assim, foi possível interagir com meus interlocutores/as de pesquisa tanto no ambiente do programa como fora dele. Voltarei a esse ponto adiante.

No Tinder, interagi com mais de 70 homens, a grande maioria dos quais tive conversas informais on-line, fosse no próprio app, fosse migrando para o Whatsapp aplicativo de troca de mensagens instantâneas que possui mais recursos para a comunicação digital (como enviar áudio ou fazer chamadas de áudio e vídeo) e se mostrou o preferido dos informantes para prolongar as conversas. No geral foram contatos mais superficiais, muito distantes de uma estrutura de entrevista, mas nem por isso menos importantes para a compreensão daquele universo relacional. Com eles, realizei duas entrevistas on-line. Outros seis destes homens encontrei e entrevistei presencialmente.

Já as interlocutoras do sexo feminino, conheci por indicação de amigos e conhecidos, ou pertenciam ao meu círculo de relações ${ }^{12}$. Também com elas o aplicativo de troca de mensagens foi importante na comunicação. Entrevistei seis dessas mulheres presencialmente.

Essas doze pessoas que encontrei presencialmente - seja para identificação mesma com participante da pesquisa, no caso das mulheres, seja para a realização das entrevistas e acompanhamento dos casos - acabaram por virar minhas interlocutoras principais. Nessa experiência de campo, percebi, sim, uma diferença com relação à qualidade das respostas, ao detalhamento das informações e à dinâmica da conversa, que fluíram melhor nos encontros analógicos do que no on-line ${ }^{13}$. Os contatos nas plataformas digitais, entretanto, foram

que buscava por outros homens em plataformas específicas para esse público (vide: MISKOLCI 2014a; 2014b; MAIA; BIANCHI, 2014; KURASHIGE 2014; KELLER; ARAÚJO; CORSO 2015; REZENDE; COTTA, 2015). Por isso, para a pesquisa defini um público que, embora figure como normativo em termos de práticas afetivosexuais, naquele momento pouco compunha a literatura acadêmica relacionada a este campo. Interessante notar, porém, que em tempos recentes usuários e usuárias vêm acusado o Tinder de promover a transfobia, a partir da exclusão sistemática dos seus perfis (Fonte: A Gazeta, 07/03/2020). Uma mostra de que, sem dúvida, as sexualidades LGBTQI+ e os usos desses apps continuam a ser um instigante tema para futuras pesquisas.

${ }^{11}$ Esse ponto difere do período em que foi feita a pesquisa para os atuais tempos de pandemia do novo coronavírus (Covid-19). Já há notícias apontando o incremento no uso desses ambientes, que figuraram como propícios para o encontro virtual, em meio à situação de distanciamento social que a doença impôs. Notícias recentes apontam o crescimento no número de matches e de conversas diárias e o prolongamento das conversas no chat, entre fevereiro e março de 2020, em plataformas desse tipo (Fonte: Portal G1, 25/05/2020).

${ }^{12}$ No aplicativo não explorei os perfis femininos para além da observação e de algumas conversas breves, pois percebi que, no geral, mulheres que ajustavam seus perfis para encontrar outras mulheres eram homo ou bissexuais, logo, meus matches femininos não entrariam no recorte da pesquisa. Daí a opção por busca-las fora do aplicativo.

13 Em um vídeo-tutorial postado em 03 de maio de 2020, em seu canal do Youtube, Daniel Miller trata sobre as potencialidades do trabalho de campo on-line durante a pandemia do novo coronavírus. Entre preciosas 
recorrentes e acabaram compondo um ambiente relacional para o estreitamento dos laços e a obtenção de dados complementares.

Desse modo, em inúmeros momentos durante o percurso do estudo me vi compelida a migrar por entre plataformas, transitar em comunicações digitais e presenciais, entre trabalho e vida cotidiana, entre cidades e estados, e parte desse fluxo on e off-line descrevo adiante.

\section{Usuários multilocalizados on e off-line}

Para Tim Ingold (2012; 2013; 2015), uma característica da condição de ser no mundo, de estar vivo, é a capacidade dos seres de sentir e responder a um ambiente que se encontra em constante fluxo. Ambiente no qual estão em relação coisas e pessoas que, contínua e reciprocamente, geram sua existência mútua, num processo dinâmico e transformativo. Sendo um ambiente digital emulado por um dispositivo móvel no qual pessoas podem identificar e se relacionar com outras que estão ao seu redor ou num raio de distância por elas estabelecido, o fluxo tende a ser uma característica essencial dos aplicativos de encontro. Internamente a ele circulam pessoas com expectativas, interesses e referências culturais muito díspares. Operando-os, as pessoas transitam por diversos aplicativos e por diferentes lugares analógicos, o que confere à pesquisa neste ambiente um caráter essencialmente multissituado (ou multilocalizado) e polifônico (MARCUS 2001; ABU-LUGHOD 2006). É um tipo de estudo etnográfico que, nos moldes do que argumenta Marcus,

(...) se incorpora conscientemente ao sistema mundo, associado atualmente com a onda de capital intelectual chamado pós-moderno, e sai dos lugares e situações locais da investigação etnográfica convencional ao examinar a circulação de dignificados, objetos e identidades culturais em um tempo-espaço difuso. (MARCUS 2001: p.111, tradução livre da autora)

Em se tratando de uma delimitação de espaços on/off para o campo, Leitão e Gomes (2011) e Parreiras (2008) propõem não realizá-la a priori, sob os argumentos de que se acompanhe o movimento dos sujeitos no campo. Para Parreiras é importante desfazer a distinção dicotômica, muitas vezes rígida e irreconciliável, entre on-line e off-line, tratando, alternativamente, das especificidades de cada ambiente como também dos seus pontos de continuação. Essa perspectiva ressoa na abordagem de estudos mais recentes, que tematizam a ideia de continuidade entre a existência on-line/off-line como um continuum (cf. MISKOLCI 2016; BELELI 2015; LEITÃO; GOMES 2018). Em termos gerais, vem-se

dicas e relatos de casos, o antropólogo fala das possibilidades de uma maior abertura das pessoas para o contato virtual com o antropólogo, num contexto no qual muitas das nossas atividades correntes apenas podem ser, agora, realizadas por esta via, em função do isolamento social (Fonte: Youtbe). Assim, o que no desenrolar do meu trabalho de campo figurou como uma limitação pode vir como potência criativa em outras circunstâncias. 
atentando para o borramento dinâmico das fronteiras do que antes era visto como "real" versus "virtual". Tal como propõe Hine (2015), a internet hoje é um fenômeno permeado, incorporado e cotidiano, no qual on-line e off-line estão conectados, fazendo sentidos diversos.

Nessa direção, Leitão e Gomes, abordando a flexibilização dos limites do campo, falam de um "deslizamento da imersão etnográfica" (LEITÃO; GOMES 2011: p.27), um deslizamento que se expande para fora das fronteiras inicialmente delimitadas como "campo" e que pode ocorrer em qualquer pesquisa antropológica. No caso das investigações da e na internet, este é um movimento de circulação entre diversas plataformas e ambientes passível de ser realizado pelos usuários/as, circuito este que elas seguiram em sua vivência de pesquisa. Sobre tal flexibilização, elas argumentam: "Estudar um mundo virtual em seus próprios termos implica reconhecer que as definições e teorias nativas sobre a distinção on e off são muito mais relevantes do que nossas definições teóricas prévias à entrada em campo" (LEITÃO; GOMES 2011: p.28).

Nos apps de encontro, essa dinâmica de circulação das pessoas (dos perfis) on-line pode se expandir para outras plataformas digitais, seja por intermédio do próprio aplicativo, seja pela migração para outros apps. No caso do Tinder, há uma convergência dos perfis com outras redes sociais do usuário, como Facebook, Instagran, Spotify, por exemplo, que permitem certos parâmetros visíveis no app. É possível deslizar por entre elas. A movimentação on-line pode ocorrer, ainda, para outras plataformas da mesma categoria. No caso dos meus entrevistados/as, Happn, Adote um Cara, Skout, OkCupid foram aplicativos utilizados em concomitância com o Tinder. Outra interface bastante acionada em concomitância com esta foi o aplicativo de troca de mensagens Whatsapp. Meus deslocamentos on-line em campo se deram também nessas direções.

Há, ainda, outra circulação, nos termos de Marcus (2001), na qual o aplicativo se insere, e que utilizei como uma das táticas para seguir o caráter multissituado dos atores sociais em campo e do próprio campo. Além de circular por distintas plataformas da internet, os usuário e usuárias têm a possibilidade de (e o decorrer da pesquisa demonstrou que o fazem) utiliza-lo durante seu trajeto ou estadia pelos seus locais analógicos de tráfego ou parada, dentro ou fora da cidade de moradia, pelo seu trânsito no mundo. Quando eu e Afonso $^{14}$ (31 anos, profissional liberal) demos match pelo Tinder, por exemplo, eu morava em João Pessoa-PB e ele estava de passagem por lá. Momentos depois do match ele iniciou uma conversa pelo app, que seguimos pelo Whatsapp durante dias, até o momento do nosso encontro para uma entrevista presencial ocorrida em Campina Grande/PB, onde ele morava. Já com Joaquim (40 anos, funcionário público), eu estava de passagem por Florianópolis-SC quando demos match e ele era morador da cidade.

Ao seguir essa característica do aplicativo, meus interlocutores/as acabaram por ser homens e mulheres brasileiros/as que conheci no Tinder ou fora dele, quando eu mesma

\footnotetext{
${ }^{14}$ Afonso foi um dos meus interlocutores de pesquisa. Seu nome e dos demais interlocutores aqui constantes foram alterados, conforme acordo com os mesmos, para manter suas identidades desconhecidas.
} 
estava nas ou circulava pelas cidades de João Pessoa-PB, Salvador-BA, e Florianópolis-SC. A grande maioria deles estava morando permanente ou temporariamente nessas cidades.

Saliento, contudo, que a opção de atrelar o grupo de pessoas que comporia a pesquisa com meus próprios ambientes de circulação não se deu com o objetivo de proporcionar uma comparação entre a dinâmica de uso em contextos urbanos específicos, tal como fizeram Miskolci (2014b) e Maia e Bianchi (2014). Por um lado, a circulação aqui é tomada como estratégia intrínseca a um estudo multilocalizado. A multilocalidade se dá "através e dentro" (MARCUS 2001: p.112) dos aplicativos, e para verificá-la optei por seguir, na medida em que me foi acessível ou se mostrou pertinente, ao menos alguns dos caminhos proporcionados por ela.

A heterogeneidade dos meus interlocutores/as decorrente da escolha metodológica em seguir essa circulação não apontou, ao final da pesquisa, para experiências marcadas em termos de traços sociológicos comuns (etnia ou gênero, por exemplo). De outro modo, mas apontou para experiências compartilhadas relacionadas tanto a experimentações de si como a modos de relacionalidade que se mostraram característicos do uso do app. Assim, este "seguir" amplificado envolveu diferentes tempos e espaços e implicou em diferentes profundidades e modalidades de relação e mesmo afecção.

Apontadas tais questões que foram centrais para o desenho metodológico da pesquisa, e tendo situado seu alinhamento à perspectiva multilocal, adentrarei um pouco no trajeto do trabalho de campo. Nele, apontarei, algumas fontes de desestabilização e certos desafios que se impuseram, em especial no que diz respeito à imersão e à abordagem da sexualidade, aspectos particularmente marcantes nesta pesquisa.

\section{Um percurso desestabilizado}

Antes de caracterizar a pós-modernidade na antropologia, movimento que fornece suporte ao seu estudo, Carolina Parreiras (2008) faz uma breve retomada histórica dos modos como o trabalho de campo e a escrita etnográfica foram reformulados, ressaltando, porém, concepções e práticas que conferiam notabilidade e legitimidade (e autoridade, conforme a crítica pós-moderna) ao trabalho do antropólogo. As correntes por ela descritas propuseram $^{15}$, à época, aspectos inovadores à teoria e prática antropológica, que dizem respeito e fazem sentido se aplicadas à antropologia analógica, nas quais é privilegiada a presença física do etnógrafo no ambiente do grupo pesquisado. Uma permanência temporalmente variável, mas significativa, que supõe observação presencial e encontro face a face, além de pressupor quase que de modo inquestionável um deslocamento territorial e simbólico até ele.

Contato presencial em campo, deslocamento territorial no sentido tradicional ou a circunscrição num dado ambiente material podem hoje ser prescindidos do trabalho de campo do antropólogo, em especial nos ambientes digitais. Isso implica em algumas

\footnotetext{
${ }^{15}$ Seriam elas: teoria crítica, cultural studies e crítica cultural. Maiores detalhes em Parreiras (2008: p.24).
} 
potenciais impossibilidades: a da atuação direta (ou plena) dos sentidos no momento da interação; a da obtenção de informações e observações diretas sobre os contextos sociais nos quais os indivíduos se encontram (ou mesmo dos seus próprios corpos físicos); a da demarcação ou cisão hierárquica e imagética do que é casa (meu lugar) e campo (lugar do outro), o aqui e o lá; a da centralidade exclusiva no humano, por estar num ambiente que pode fundi-lo com outras formas de presença (os aparatos técnicos, por exemplo) e possibilita tanto sua estadia ali como o contato com o outro (PARREIRAS 2008; LEITÃO; GOMES 2011; 2018; PELÚCIO 2016).

Entretanto, tal como propõem Miller e Slater (2004), a etnografia on-line encerra elementos metodológicos marcantes do trabalho etnográfico analógico, como a participação, o diálogo, a observação, o texto. A estes são somadas especificidades analíticas: os autores ressaltam a importância da observação dos diversos contextos (on-line e off-line) que se relacionam e superpõem para alcançar os objetivos específicos dos estudos.

Já Leitão e Gomes (2011), ao responder às reflexões sobre trajeto e alteridade feitas por James Clifford em face à sua própria pesquisa em ambientes digitais imersivos $3 \mathrm{D}^{16}$, lembram que nas análises antropológicas na e da internet a tecnologia tanto é o meio de transporte para o campo como é o próprio ambiente do campo. Seu deslocamento feito pela imersão - no caso delas, uma imersão dividuada entre seus corpos biológicos, na operação cognitivo-gestual do maquinário informático e na interação com os outros naquele meio, e a atuação dos seus avatares (corpos virtuais) no cenário do mundo digital.

No caso desta pesquisa, a imersão, mais que observar e acompanhar, implicou em estar a todo momento, em qualquer horário ou situação da minha vida cotidiana, inserida no ambiente do meu campo empírico, disponível a ele. Tecnologias comunicativas como o mobile e os aplicativos de paquera e troca de mensagens estabelecem dinâmicas de interações diferentes das tradicionais (DI FELICE 2007), inclusive, com relação à própria internet em períodos anteriores. Já não mais entramos on-line esporadicamente; nós vivemos on-line, fragmentamos ao longo do nosso dia inúmeras interações instantâneas com/nas diversas interfaces digitais. Ramos (2015) nos lembra o conceito cunhado por Sherry Turkle do Eu amarrado, conectado on-line:

Em primeiro lugar, esta conexão é realizada através de uma estrutura técnica que está em funcionamento contínuo. Em segundo lugar, essa estrutura técnica pode, ela mesma, enviar e receber continuamente mensagens, o que faz com que a conexão passe da potência à ação, por meio da máquina. Em terceiro lugar, o agente conectado está continuamente disponível para receber e enviar mensagens. Assim, essa

\footnotetext{
${ }^{16}$ Segundo Mello Sobrinho (2011: p.25) são "ambientes virtuais interativos tridimensionais, especificamente construídos a partir de um cenário (via reprodução digital de um cenário autêntico ou, pelo contrário, total ou parcial ente criado ad hoc) através do qual o usuário pode movimentar um avatar (seu personagem ou representação no mundo virtual) ou movimentar-se com um ângulo/visão de primeira pessoa”.
} 
conexão não é uma metáfora. Quando o indivíduo avisa outros de que está em seu celular, isto significa que ele vai carregá-lo e pode ser encontrado o tempo todo, mas também significa que este EU está continuamente na rede. (RAMOS 2015: p.63)

A partir do momento em que se tem um perfil ativo no Tinder e se adiciona os usuários nos seus contatos do Whatsapp, por exemplo, as pessoas ganham acesso umas às outras, potencialmente, quando quiserem. Nesse sentido, a imersão não diz respeito apenas aos atos da pesquisadora em relação ao seu campo e informantes, mas, também, à reciprocidade do acesso e intensidade da interação na sua vida pessoal.

O sociólogo Keith Kurashige, ao falar dos procedimentos metodológicos de sua pesquisa sobre critérios raciais na busca por relações homoeróticas masculinas em chats usados numa cidade paulista, narra uma dinâmica similar à vivenciada por mim nesta pesquisa:

Neste período, criei laços de afinidade com meus colaboradores, e, como se trata de uma etnográfica mediada por mídias digitais, estive sempre conectado a eles por meio do telefone celular ou computadores, podendo ser solicitado a interagir quando bem quisessem. Dessa forma, assim como Facioli (2013) em seu campo, no qual também esteve conectada por meio das mídias digitais, "pareceu impossível, na rede, o distanciamento do campo e dos sujeitos, durante a pesquisa”. (KURASHIGE 2014: p.51-52)

Não se trata de uma etnografia que o pesquisador volta para a casa quando se cansa, mas, até mesmo quando o pesquisador está dormindo, uma notificação de celular o instiga a interagir. Se, como pontuou Geertz (2001), o trabalho de campo antropológico obriga a fundir o que seria a divisão entre trabalho e vida corrente, estudando as dinâmicas dos apps de paquera vivi um fluxo no qual eu não apenas "fui ao campo", mas estava potencialmente todo o tempo em campo, em estado on-line, e ele comigo, em meu celular.

Assim, estar imerso numa plataforma que lhe geolocaliza on-line, lhe notifica da interação de outros ao longo do seu dia a dia e aciona outros a interagir com você é estar em estado de presença potencialmente constante, ou, na palavra de Pierre Lévy (1999, p. 127), de "telepresença generalizada". E essa presença demanda ação e interação distintas, pois cada ambiente digital produz seus modos específicos de integrar, solicita uma inserção e atuação diferenciadas.

A imersão, portanto, é o que produz presença, participação e interação: a sensação da sua presença e da do outro. Mesmo em ambientes digitais que não possuem a prerrogativa de simulação de mundos virtuais, a imersão se mostra a tônica da "viagem experiencial" (HINE 2004) proporcionada pelo/até o campo digital. Em Etnografia em Ambientes Digitais: perambulações, acompanhamentos e imersões, Débora Leitão e Laura Gomes 
tecem interessantes considerações sobre diferentes abordagens etnográficas em ambientes digitais, demandadas pelas diferenças estruturais das dinâmicas das distintas plataformas. Elas compreendem que, diferente das preambulações e acompanhamentos, a imersão se daria em arquiteturas digitais que proporcionam agenciamentos suficientemente fortes para influir nos regimes de self dos participantes, inclusive pesquisadores, o que não seria o caso dos aplicativos aqui estudados. Como proposto neste trabalho, todo o processo dialógico de interação, aprendizado, construção de intensas relações é proporcionado por um campo que também aciona desejos íntimos e emoções ajustados um ambiente no qual a imersão pode se estabelecer. E tal distinção talvez esteja tanto ligada ao potencial agenciador das plataformas como ao modo pelos quais o pesquisador se conecta a elas.

Assim, quanto mais imerso, mais se compreende como se atuar lá, se aprende como as relações ocorrem, as formas de seduzir o outro (ou de evitá-lo, quando o contato lhe é inoportuno). E num campo de disputa por atenção e afetividade, para se manter um contato ativo é preciso estar disponível, logado, atento, sedutor, presente no aplicativo de paquera, no aplicativo de troca de mensagens, na rede social.

Pesquisando no âmbito da sexualidade e dos afetos por meio dos aplicativos de encontro, Pelúcio (2016) fala da exigência imersiva como um dos pontos metodológicos desafiadores daquela pesquisa. A imersão lhe conferiu uma sensação de hiperconexão e pertencimento àquele mundo: "Nunca fui tão nativa" (PELÚCIO 2016: p.310). Um pertencimento inquietante que a desestabilizou como pesquisadora e pessoa.

Pelúcio traz para o debate, dentre outros aspectos, que a imersão num ambiente digital de paquera encerra a exigência de uma interação em níveis emocionais intensos, um desnudar-se da pesquisadora para a mulher, solicitando-lhe uma postura menos "acadêmica" e mais "pessoal”. Isso não como estratégia de negociar o aprofundamento do contato, mas porque "vai-se construindo relações densas" (ibidem: p.322) nos diálogos iniciados nos aplicativos. Diálogos que poderiam findar tão rapidamente como se iniciaram, ou perdurar por semanas. Interações que adentraram seu lar - ou a sua privacidade num sentido mais amplo - porque o seu campo está em seu celular - e ela está nos celulares dos seus interlocutores, que a acionam nos momentos em que eles quiserem e motivados por interesses diversos. Ambos, pesquisadora e interlocutores, estavam fazendo investimentos emocionais naqueles contatos.

Pude perceber que essa é uma dinâmica relacional característica desses ambientes de exposição e negociação de afetos, desejos e intenções. $\mathrm{O}$ ambiente de hiperconexão e investimentos emocionais de que trata a autora é semelhante ao que atuei. Como ela propôs, observei que aquele também é lócus de aprendizado: sobre como lidar com a tecnologia (configurar e transitar pelos programas, fazer perfis virtuais etc.), como negociar dentro dele sexo e afetos e como ambos, tecnologia e emotividade, jogam para configurar um mapa dos desejos e afeições na atualidade. Ao ter esse contexto como campo de pesquisa, somos pesquisadores e pessoas (desejáveis e desejosas) dentro dele. Quando damos match num aplicativo de encontros, avaliamos e passamos pela avaliação do outro que, de certo modo, 
tem (e constrói ou desconstrói no contato) expectativas e curiosidades múltiplas ao nosso respeito, muitas delas relacionadas ao foro íntimo.

Afonso foi uma das primeiras pessoas com quem conversei mais longamente on-line no período do campo. Em nossos primeiros diálogos, ao tempo em que ele questionava sobre a pesquisa e discorria sobre suas histórias e impressões acerca do aplicativo e dos relacionamentos, me fazia perguntas pessoais (se eu já havia me envolvido com pessoas do aplicativo, qual a minha altura...) e me pedia fotos de corpo inteiro. Ele foi o primeiro a me sinalizar as tensões que a pesquisa de campo poderia exercer sobre a antropóloga no processo de estabelecimento das margens, dos limites entre trabalho e prazer, conversa e paquera, cooperação e sedução, as minhas expectativas e interesses e os dos interlocutores, em especial do sexo masculino. Para estes, enviar ou receber material visual íntimo ou com conteúdo explicitamente erótico poderia ser uma prática usual na construção das relações a partir daquele espaço. Intimidade (ou a tentativa de estabelecê-la) e sedução são linguagens faladas nos contatos iniciados nos aplicativos e, certamente, a pesquisadora não ficaria imune a elas.

O encontro com João (39 anos, músico), outro dos meus interlocutores, proporcionou mais um momento liminar na pesquisa, no qual expectativa e desejos precisaram ser negociados. Após as conversas virtuais iniciais, agendamos uma primeira entrevista. Ao seu final, João, para minha surpresa e embaraço, deu-me um beijo na boca como despedida. O gesto me balançou emocionalmente, mas, também e principalmente, mexeu com minhas certezas profissionais. Senti uma enorme inquietação ética com o episódio. Questionei minha metodologia: seria o contato presencial, de fato, uma boa tática? Questionei minha postura: estaria eu preparada para lidar com esse tipo de situação, que no face a face se tornava mais difícil de contornar que na interação digital? Com João, conversei, e tranquilamente ajustamos os termos da nossa interação para adiante. Com a pesquisa, mantive a metodologia, e utilizei o fato como uma fonte de atenção e como uma estratégia para lidar com interlocutores que, a partir daí, tencionaram a relação para algo além da colaboração ou da amizade: eu narrava o evento ocorrido com João, falando do meu constrangimento e das possíveis implicações negativas para a pesquisa com episódios como aquele. A narrativa serviu para desencorajar futuras tentativas, que não tardaram a acontecer.

Oliveira (2016), Meinerz (2006) e Rojo (2004), tratando de pesquisas bastante distintas, mas inseridas nos campos da efetividade ou sexualidade, abordaram sobre as expectativas sexuais, afetos e intimidade que o contato com os sujeitos em campo lhes propiciou ou lhes tensionaram, e as implicações disto nas investigações que faziam. Assim como Pelúcio, eles foram unânimes em salientar esta como uma característica marcante (apesar de não ser exclusiva) neste tipo de estudo. Num campo onde se está em jogo intenções e expectativas afetivo-sexuais, o pesquisador - um ser como outro, que tem gênero e sexualidade localizados pelos interlocutores/as - é compelido a "jogar". E efetivamente pode se ver jogando, ou, parafraseando Pelúcio, pode ser capturado pelas teias desejantes. 
Zago e Santos (2011) denominaram de "método consensual de pesquisa" uma postura ético-metodológica que privilegia flexibilização e construção consensual conjunta entre pesquisadora e pesquisados dos limites relacionais da pesquisa. Nas experiências dos três pesquisadores citados, situações de intimidade ou envolvimento emocional durante o trabalho de campo foram determinantes para a compreensão de e a entrada em aspectos específicos do campo, que não teriam acesso de outro modo. E, me parece, tais situações só puderam ocorrer porque eles foram identificados pelos seus pares como sujeitos passíveis não (apenas) às regras e ética da pesquisa de campo antropológica, mas às regras do próprio campo, inclusive em suas possibilidades relacionais de afeto e afetação.

Nesse sentido, em minha vivência, notei que apenas quando era solicitada a falar sobre as minhas experiências ou pontos de vista pessoais sobre o Tinder - aqueles momentos em que se desliga o gravador e a entrevista vira uma conversa entre pares - fui reconhecida como alguém a quem se podia contar certos detalhes a mais, porque sabia do que eles estavam falando. Goldman chamou a atenção sobre essa possibilidade quando comentou as afecções descritas por Favret-Saada: "Foi apenas quando alguém diagnosticou que a etnógrafa fora 'pega' (prise) pela feitiçaria que passou a fazer algum sentido falar com ela sobre o assunto" (GOLDMAN 2005: p.13). Como usuária, eu reconhecidamente também havia sido "enfeitiçada" pelo Tinder.

O credenciamento como pesquisadora insider (FRAGOSO; RECUERO; AMARAL 2011) de um ambiente de busca por parceiros ante os meus interlocutores/as ganhou sentidos diversos e intercambiáveis: ora implicando em franca cooperação; ora como troca de conteúdos pouco comentados, ou de segredos (SIMMEL 1999) que precisavam ser ditos ou refletido entre/com quem já experimentou algo parecido; ora em vislumbres de possibilidades que poderiam se estender para além da conversa, seja para um terreno afetivo (o que envolveria a amizade ou coleguismo), seja em termos sexuais. Essa intimidade tensa e negociada foi uma das marcas das relações que se estabeleceram entre mim e meus interlocutores/as, e cujos limites foram se fazendo de modo diferenciado com cada pessoa ao longo do processo.

\section{Considerações Finais}

Ao longo deste texto apresentei alguns dos modos de fazer e desafios enfrentados na pesquisa de campo que realizei no Tinder, com usuários e usuárias. Nas relações propiciadas pelo aplicativo e pelos deslizamentos para outros ambientes digitais e encontros presenciais foram recorrentes e/ou marcantes algumas situações elencadas. Dentre elas, conversas e entrevistas em distintos ambientes digitais e presenciais; matches com pessoas de diferentes cidades, algumas das quais se encontravam muito distantes espacialmente; impasses e tensões relativas às expectativas de interação afetiva/sexual que caracterizam as relações no aplicativo; conversas estendidas a um tom pessoal desconcertante, que tornam a pesquisadora também foco da avaliação dos interlocutores/as da pesquisa; recebimento ou pedidos de materiais audiovisuais inusitados ou mesmo com conteúdo íntimo ou erótico 
explícito; tentativas de experimentar estratégias de abordagem diversas, que preservassem a privacidade da pesquisadora, mas não quebrassem a construção de intimidade característica dos contatos possibilitados naqueles cenários. Alguns desses eventos são característicos do fazer etnográfico, e outros não são específicos da cena de pesquisa; de outro modo, argumento, estão inseridos nos devires das interações que se estabelecem mediadas pelos aplicativos, fazem parte dos modos como os eventos vãos se dando a partir deles.

Ao levar em conta, como propôs Peirano (1992: p.4), que o trabalho de campo em antropologia é tanto mito como parte do desenvolvimento histórico da disciplina, compreenderemos que sua forma não poderia ficar incólume às modificações no tempo dos contextos socioculturais nos quais o antropólogo se debruça. As tecnologias digitais acabaram por ser uma dessas modificações que incitam à incorporação ativa e criativa de novas metodologias, estratégias e ferramentas no fazer etnográfico, como apontam para desafios, muitos dos quais éticos ou afetivos, a serem enfrenados em diálogo com as pessoas envolvidas e as próprias possibilidades e modos de atuação característicos de cada um desses ambientes relacionais. De acordo com Peirano (1994: p.209), "consciente ou não, cada monografia/etnografia é um experimento".

Por fim, optei por expor esses aspectos dos fazeres e devires da minha experiência de campo por pretender colaborar com a troca de conhecimentos e experimentações advindos da prática antropológica e dos modos de lidar com as surpresas que esta enseja. Mas também como mais um exercício do "desnudar-se" propiciado pela pesquisa etnográfica. Um desnudar-se que tanto pode cooperar com o sempre autorreflexivo fazer da disciplina, como compor e reavivar debates de temas muitas vezes semicerrados, como o envolvimento, em vários níveis, inclusive afetivos e sexuais, dos sujeitos numa dada cena relacional que convencionamos chamar de trabalho de campo. Trago aqui uma provocação para debatermos se a opção entre fazer pesquisa ou tornar íntima uma interação proporcionada pelos aplicativos de paquera é, de fato, algo tão dicotômico como aparenta.

\section{Referências Bibliográficas}

ABU-LUGHOD, Lila. (2006). Interpretando la(s) cultura(s) después de la televisión: sobre el método. Íconos Revista de Ciencias Sociales, Quito, n. 24, p. 119-141.

BELELI, Iara. (2015). O imperativo das imagens: construção de afinidades nas mídias digitais. Cadernos Pagu, 44, p. 91-114.

BOZON, Michel. (2004). Sociologia da sexualidade. Rio de Janeiro: FGV.

CAVALCANTE, Sheila. (2019). Curtir ou não curtir: experimentações a partir do Tinder. Dissertação de mestrado em Antropologia. João Pessoa: PPGA/UFPB.

DI FELICE, Massimo. (2007). As formas digitais do social e os novos dinamismos da sociabilidade contemporânea. In: KUNSCH, Margarida; KUNSCH, Waldemar. (Orgs). Relações Públicas Comunitárias. São Paulo: Summus Editorial. 
DIJCK, Jan van. (2016). La cultura de La conectividad: una história crítica de las redes sociales. Buenos Aires: Siglo Veintiuno Editores.

FRAGOSO, Suely; RECUERO, Raquel; AMARAL, Adriana. (2011). Métodos de pesquisa para internet. Porto Alegre: Sulina.

GEERTZ, Clifford. (2001). "O pensamento como ato moral: dimensões éticas do trabalho de campo antropológico nos países novos”. In. GEERTZ, Clifford. Nova luz sobre a Antropologia. Rio de Janeiro: Jorge Zahar Editor.

GIDDENS, Anthony. (1993). A transformação da intimidade: sexualidade, amor e erotismo nas sociedades modernas. São Paulo: Editora Unesp, 1993.

GOLDMAN, Marcio. (2005). Jeanne Favret-Saada, os afetos, a etnografia. Cadernos de Campo, n 13, p.149-153.

HINE, Christine. (2015). Ethnography for the Internet: embedded, embodied and everyday. London: Bloomsbury.

ILLOUZ, Eva. (2011). Amor nos tempos do capitalismo. Rio de Janeiro: Zahar.

INGOLD, Tim. (2015). Estar Vivo: ensaios sobre movimento, conhecimento e descrição. Petrópolis: Vozes.

INGOLD, Tim. (2013). Repensando o animado, reanimando o pensamento. Espaço Ameríndio, v. 7, n. 2, p. 10-25.

INGOLD, Tim. (2012). Trazendo as coisas de volta à vida: emaranhados criativos num mundo de materiais. Horizontes Antropológicos, ano 18, n. 37, p. 25-44.

KELLER, Daniel Gevehr; ARAÚJO, Denise Castilhos de; CORSO, Aline. (2015). Ciberterritórios e masculinidades: o papel do discreto no aplicativo Scruff. Conexão Comunicação e Cultura, vol.14, n.27, p. 153-179.

KURASHIGE, Keith. D. Marcas do desejo: um estudo sobre os critérios de raça na seleção de parceiros em relações homoeróticas masculinas criadas online na cidade de São Carlos. Dissertação de Mestrado em Ciências Humanas: São Carlos: UFSCar, 2014.

LEITÃO, Débora Krischke; GOMES, Laura Graziela. (2011). Estar e não estar lá, eis a questão: pesquisa etnográfica no Second Life. Cronos, v.12, n.2, p. 23-38.

LEITÃO, Débora Krischke; GOMES, Laura Graziela. (2017). Etnografia em Ambientes Digitais: perambulações, acompanhamentos e imersões. Revista Antropolítica, n.42, p.41-65

LEITÃO, Débora Krischke; GOMES, Laura Graziela. (2018). Gênero, sexualidade e experimentação de si em plataformas digitais on-line. Civitas, v. 18, n.1, p.171-186.

LÉVY, Pierre. (1999). Cibercultura. São Paulo: Editora 34, 1999.

MAIA, João; BIANCHI, Eduardo. (2014). Tecnologia de geolocalização: Grindr e Scruff redes geosociais gays. Revista Logos. v. 2, n. 24.

MARCUS, George. (2001). Etnografía en/del sistema mundo. El surgimiento de la etnografía multilocal. Alteridades, v.11, n. 22, p. 111-127, 2001. 
MARCUS, George. (2004). O intercâmbio entre arte e antropologia: como a pesquisa de campo em artes cênicas pode informara reinvenção da pesquisa de campo em Antropologia. Revista de Antropologia, São Paulo, USP, v. 47, n. 1, 2004.

MELLO SOBRINHO, Evaldo Carneiro de. (2011). Ambientes Virtuais Imersivos: a perspectiva de pesquisadores em relação à linguagem e à tecnologia. Dissertação de Mestrado em Lingüística Aplicada. Rio de Janeiro: UFRJ.

MILLER, Daniel; HORST, Heather. (2015). O Digital e o Humano: prospecto para uma Antropologia Digital. Parágrafo, v. 2, n. 3.

MILLER, Daniel; SLATER, Don. (2004). Etnografia on e offline: cybercafés em Trinidad. Horizontes Antropológicos, v. 10, n. 21, p. 41-65.

MISKOLCI, Rirchard. (2014a). San Francisco e a nova economia do desejo. Lua Nova, 91. São Paulo, p. 269-295.

MISKOLCI, Rirchard. (2014b). Negociando visibilidades: segredo e desejo em relações homoeróticas masculinas criadas por mídias digitais. Bagoas, v. 8, n. 11, p. 51-78.

MISKOLCI, Rirchard. (2016). Sociologia Digital: notas sobre pesquisa na era da conectividade. Contemporânea, v. 6, n. 2 p. 275-297.

OLIVEIRA, Thiago de Lima. (2016). Engenharia Erótica, arquitetura de prazeres: cartografias da pegação em João Pessoa. Dissertação de Mestrado em Antropologia. João Pessoa: Universidade Federal da Paraíba.

PARREIRAS, Carolina. (2008). Sexualidades no ponto.com: espaços e homossexualidades a partir de uma comunidade on-line. Dissertação de Mestrado em Antropologia Social. Campinas: Universidade Estadual de Campinas.

PEIRANO, Mariza. (1992). A favor da etnografia. Brasília, 1992. Disponível em http://naui.paginas.ufsc.br/files/2010/09/Peirano_a-favor-da-etnografia.pdf.

PEIRANO, Mariza. A favor da etnografia. Anuários Antropológicos: 1992. Rio de Janeiro, Tempo Brasileiro, p. 197-223.

PELÚCIO, Larissa. (2016). Afetos, mercado e masculinidades contemporâneas: notas iniciais de uma pesquisa em aplicativos móveis para relacionamentos afetivos/sexuais. Contemporânea, v. 6, n. 2, p. 309-333.

RAMOS, Jair de Souza. (2015). Subjetivação e poder no Ciberespaço: da experimentação à convergência identitária na era das redes sociais. Revista Vivência, n.45, p.57-76.

REZENDE, Renata; COTTA, Diego. (2015). “Não curto afeminado”: homofobia e misoginia em redes geossociais homoafetivas e os novos usos da cidade contemporânea. Comunicação e cultura, v. 13, n. 02, p. 348-365.

ROJO, Luiz Fernando. (2004). Rompendo Tabus: a subjetividade erótica no trabalho de campo. Cadernos de Campo, n. 12, p. 41-56.

SANTAELLA, Lucia. (2014). A Web em perspectiva. In: SANTAELLA, Lucia. Comunicação ubíqua: Repercussões na cultura e na educação. São Paulo: Pia Sociedade de São Paulo, Editora Paulus. 
SCHÜTZ, Alfred; LUCKMANN, Thomas. (2003). Las estructuras del mundo de la vida. Buenos Aires: Amorrortu Editores, p.7-40.

SIMMEL, Georg. (1999). O Segredo. Revista Política \& Trabalho, vol.15, p.221-226.

SIMMEL, Georg. (2005). O estrangeiro. Revista Brasileira de Sociologia da Emoção, v.4, n.12.

SILVA, Gilson Peres Tosta da. (2016). Possíveis contribuições das redes sociais mediadas pela internet para os relacionamentos amorosos. Multiverso, v. 1, n. 2, p. 181-195.

SILVA, Vergas Vitória Andrade da; TAKEUTI, Norma. (2010). Romance na Web: formas de experimentar o amor romântico num namoro virtual. RBSE, vol. 26, n.9, p. 398-451.

SILVA, Vergas Vitória Andrade da. (2009). O amor em tempos de internet: reflexões sobre subjetividade e a ausência de corpos nas relações amorosas virtuais. XVII SEMANA DAS HUMANIDADES. 1 a 5 junho, 2009, Rio Grande do Norte.

VELHO, Gilberto. (1981). Individualismo e cultura: notas para uma antropologia da sociedade contemporânea. Rio de Janeiro: Zahar Editores.

VELHO, Gilberto. (2003). Projeto e metamorfose: antropologia das sociedades complexas. Rio de Janeiro: Jorge Zahar.

ZAGO, Luiz Felipe; SANTOS, Luis Henrique Sacchi dos. (2011) Corpo, gênero e sexualidades gays na corda bamba ético-metodológica: um percurso possível de pesquisa na internet. Cronos, Natal, v.12, n. 2, p. 39-56.

\section{sobre a autora}

\author{
Sheila Cavalcante \\ É mestra em Antropologia pelo Programa de Pós- \\ graduação em Antropologia da Universidade Federal \\ da Paraíba e atualmente doutoranda pelo Programa de \\ Pós-Graduação em Antropologia da Universidade \\ Federal do Paraná.
}

Recebido em 28/09/2020

Aceito para publicação em 22/12/2020 